\title{
Informe preliminar 2: Gestión de Incendios Forestales durante COVID-19, Resultados de la encuesta
}

\author{
Cathelijne R. Stoof ${ }^{1}$, Jasper R. de Vries ${ }^{2}$, P. Marijn Poortvliet ${ }^{2}$, Bethany Hannah ${ }^{3}$, Ron Steffens ${ }^{4}$, Peter \\ Moore $^{5}$
}

${ }^{1}$ Department of Environmental Sciences, Wageningen University, The Netherlands. ${ }^{2}$ Strategic Communication Group, Wageningen University, The Netherlands. ${ }^{3}$ The American Wildfire Experience, USA. ${ }^{4}$ Wildfire Magazine, International Association of Wildland Fire; Prescott College, USA. ${ }^{5}$ Food and Agriculture Organization of the United Nations, Rome, Italy

Traducido del Inglés al Español por Isabeau Ottolini, Internet Interdisciplinary Institute (IN3), Open University of Catalonia, Spain

\section{Resumen}

La gestión de los incendios forestales se ve afectada por COVID-19 debido a los requisitos estrictos de higiene y distanciamiento social. En el presente informe damos un adelanto de los resultados de la encuesta en línea (enlace) que fue realizado para aclarar qué implicaciones tienen las restricciones de COVID-19 sobre la gestión de los incendios forestales; mapear las ideas iniciales; y recopilar cualquier plan, protocolo o procedimiento, con la finalidad de elaborar una guía genérica a usar por los profesionales en incendios forestales. La encuesta fue completada por 443 personas de más de 38 países, que trabajan en una gran variedad de organizaciones en términos de tipo de organización; nivel de jurisdicción; función primaria; y el tamaño de las unidades dedicados a la gestión y supresión de incendios. En este informe preliminar están los resultados preliminares más importantes. En resumen, los datos indican una preocupación por los efectos de COVID-19 en la gestión de los incendios forestales y se prevé que impedirá la gestión. A pesar de ello, hay una gran confianza en que se puedan continuar las operaciones durante la pandemia. Los requisitos de higiene y distanciamiento de COVID-19 se están adoptando ampliamente, quedando reflejado en un menor número de personal por vehículo. Se prevé una reducción de los servicios de apoyo disponibles. Cabe mencionar, además, la reducción prevista en el intercambio y la recepción de recursos (desde y hacia otros países o regiones) en tiempos de necesidad. Por último, las actividades de capacitación y de reducción de riesgos también se ven afectadas, lo que sugiere que la pandemia tendrá un impacto a largo plazo sobre la gestión de incendios. Dos preocupaciones principales destacadas por los encuestados son la falta de pruebas rápidas de COVID-19 entre los bomberos forestales, y el aumento del riesgo de accidentes de vehículos al repartir el personal entre más vehículos. Estamos analizando ahora la riqueza de las respuestas, incluyendo más de 30.000 palabras de comentarios compartidos, y tenemos previsto publicar el análisis completo a mediados de junio.

Por favor, cite este informe preliminar como: Stoof, C.R., De Vries, J.R., Poortvliet, P.M., Hanna, B., Steffens, R. Moore, P. (2020). Informe preliminar 2: Gestión de Incendios Forestales durante COVID19, Resultados de la encuesta. Universidad de Wageningen, Países Bajos. Traducido por Isabeau Ottolini https://doi.org/10.18174/524946

El Informe 2 completo estará disponible en https://doi.org/10.18174/521465

Autores correspondientes: Peter.Moore@fao.org; Cathelijne.Stoof@wur.nl

Este trabajo está licenciado bajo una Licencia Internacional de Atribución 4.0 de Creative Commons. Esto permite al usuario redistribuir, crear derivados, como una traducción, e incluso utilizar la publicación para actividades comerciales, siempre que se dé el crédito apropiado al autor (BY) y que el usuario indique si la publicación ha sido modificada. Para los términos de la licencia, ver aquí. 
Se buscan traductores: Buscamos personas que quieren traducir nuestros informes para poder comunicar este material a un público más amplio. Si usted está interesado (cualquier idioma es bienvenido), por favor contacte a los autores correspondientes para la versión Word de este informe.

\section{Tabla de Contenidos}

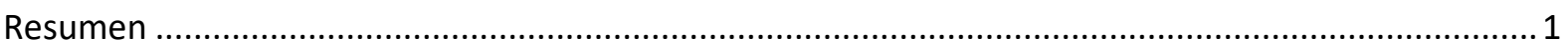

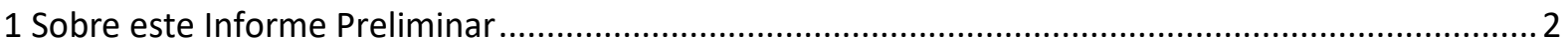

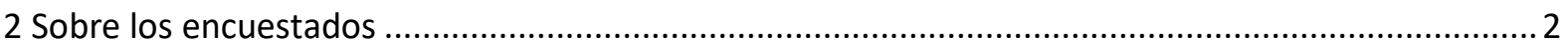

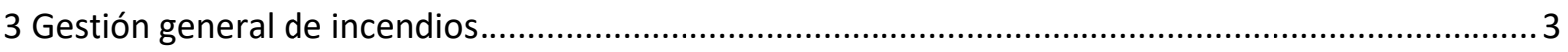

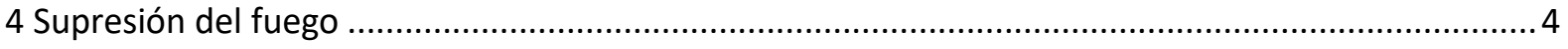

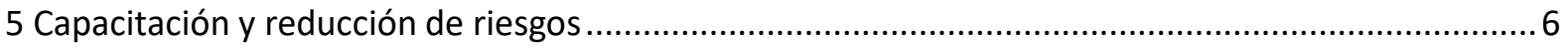

6 Necesidad de pruebas rápidas de detección ...............................................................................

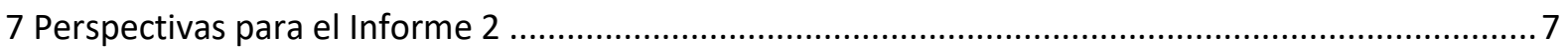

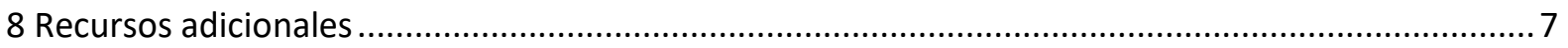

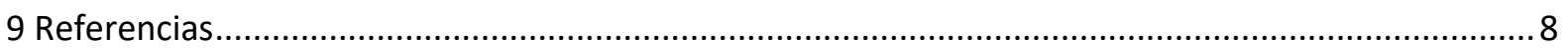

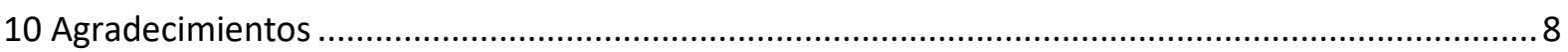

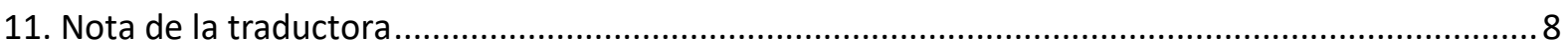

\section{Sobre este Informe Preliminar}

El objetivo de este Informe Preliminar es publicar rápidamente las conclusiones más importantes de la encuesta en línea sobre la gestión de incendios forestales durante el COVID-19. La encuesta fue compartida con la comunidad global de profesionales en incendios forestales en abril y mayo de 2020, y su objetivo era recopilar materiales; aclarar implicaciones de las restricciones de COVID-19 sobre la gestión de incendios forestales; trazar un mapa de ideas actuales; y crear conciencia sobre el tema. Este documento es un adelanto del Informe 2, el cual presentará todos los resultados del estudio, siendo ésta la segunda parte de una serie de informes que comenzó con la revisión de materiales orientativos sobre incendios forestales y COVID-19, publicado a principios de mayo de 2020 (Moore et al, 2020).

Dado que esto es un informe preliminar, los resultados compartidos aquí son preliminares. Los detalles aún pueden cambiar porque las preguntas con categorías de "otros, por favor especifique" no han sido recopilados aquí. No obstante, compartimos estos primeros resultados preliminares para permitir un rápido aprendizaje durante esta pandemia. Para los números y análisis finales, por favor consulte nuestro Informe 2 que se publicará aquí a mediados de junio de 2020.

\section{Sobre los encuestados}

El estudio fue completado por 443 personas de más de 38 países (Fig. 1). Todos los continentes están representados, y además participaron encuestados de varios países templados, abarcando con un territorio más allá de los países 'típicos' con incendios forestales. Sobre un $40 \%$ de los encuestados están en los EE. UU., muy por encima de cualquier otro país. España, Italia, Sudáfrica, Australia, Canadá y Portugal componen el siguiente $20 \%$ (y otro $20 \%$ no contestó a esta pregunta). 
La mayoría de los encuestados se dedican a la gestión de los incendios forestales, y una proporción menor se dedica tanto a la gestión de incendios forestales y estructurales. El tamaño total del personal de las organizaciones representadas en la encuesta oscila entre 1-10 y $>500$, con una gran dispersión también en el número de personal de gestión y de extinción de incendios. La mayoría de los encuestados trabajan para organizaciones gubernamentales. El nivel de las jurisdicciones va desde el nivel provincial/estatal al nacional, local e internacional, en orden de frecuencia decreciente. Siete de los encuestados trabajan para organismos tribales. La gestión de incendios y del paisaje son las funciones primarias y secundarias más frecuentes, seguido por los servicios de emergencia.

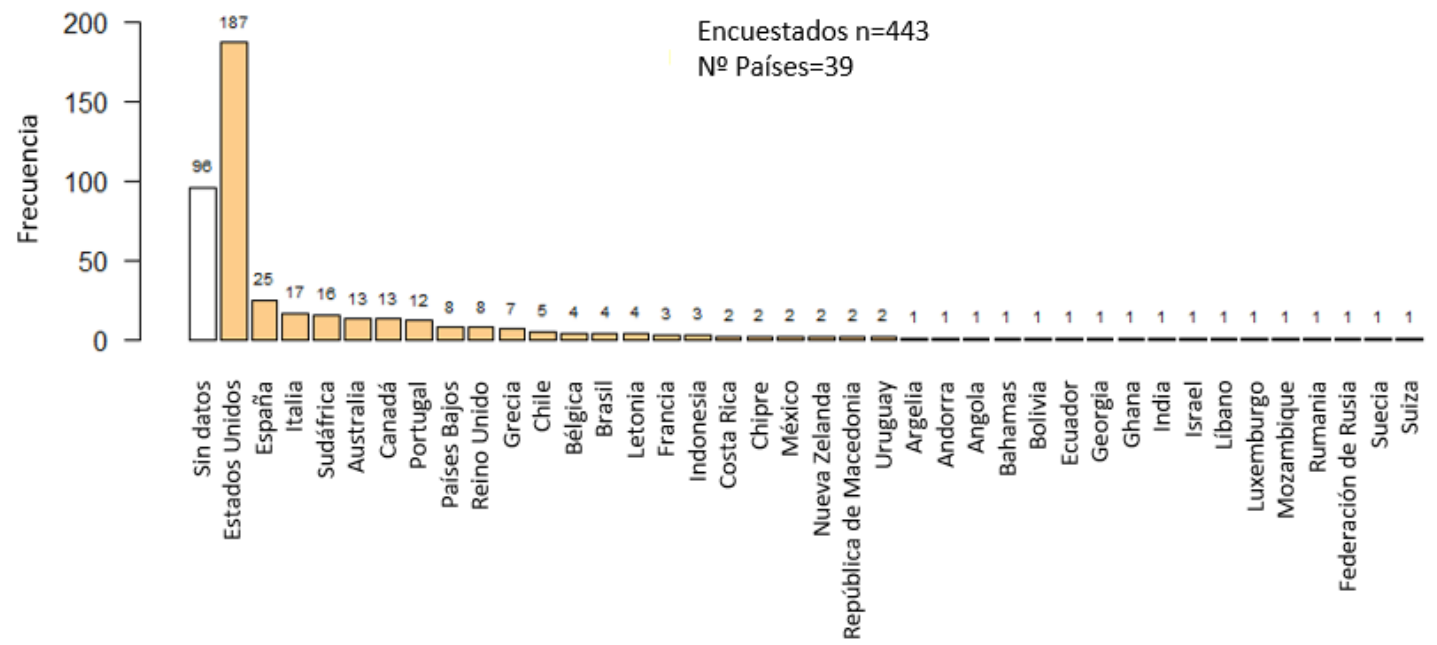

Figura 1. Panorama preliminar de los países de los encuestados

\section{Gestión general de incendios}

Los datos muestran que existe una gran preocupación por el impacto de COVID-19 en el funcionamiento de las organizaciones de los encuestados, y que se prevé que COVID-19 tenga un impacto considerable sobre la gestión de los incendios (Fig. 2). Además, los resultados de las preguntas abiertas muestran una gran incertidumbre sobre el impacto de las medidas de COVID-19 en el futuro, ya que la temporada de incendios o bien aún no han comenzado o bien las medidas están sujetas a cambios constantes. No obstante, existe una gran confianza en que las organizaciones representadas puedan realizar las tareas de gestión de incendios durante la pandemia (Fig. 2).
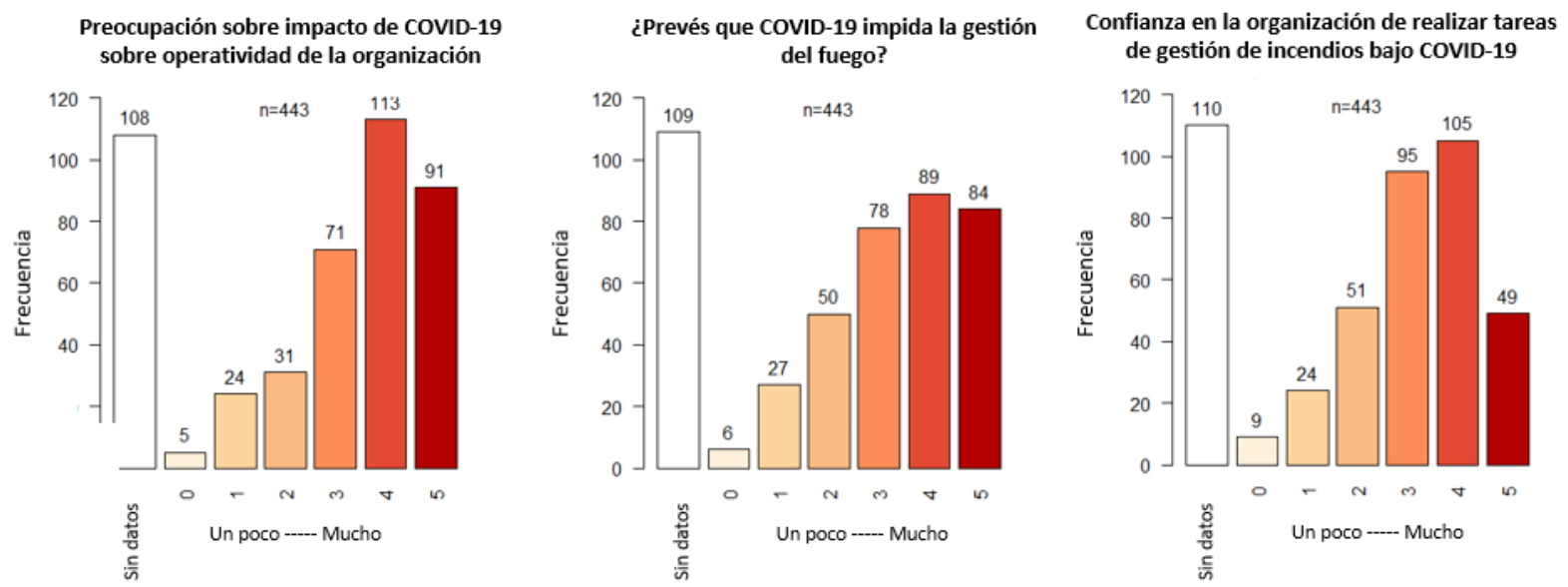

Figura 2. Percepción (preliminar) de los efectos de COVID-19 en la gestión general de incendios. Aquí n indica el no de encuestados 


\section{Supresión del fuego}

Queda evidente que las medidas contra COVID-19 se están adoptando ampliamente entre las organizaciones de los encuestados. De las 310 personas que respondieron a esta pregunta, la gran mayoría han adoptado medidas de distanciamiento social, seguido por medidas de higiene; desinfección y limpieza; y control del tamaño del grupo (Fig. 3a). Los datos también muestran que se prevé que COVID-19 reduzca la disponibilidad de servicios de apoyo (por ejemplo, logística y suministro; servicios de restauración; mantenimiento y suministro de la aviación; alojamiento; transporte); seguido de otros servicios; $y$, en menor medida, de servicios especializados (por ejemplo, meteorología, calidad del aire, teleobservación); Fig. 3b).
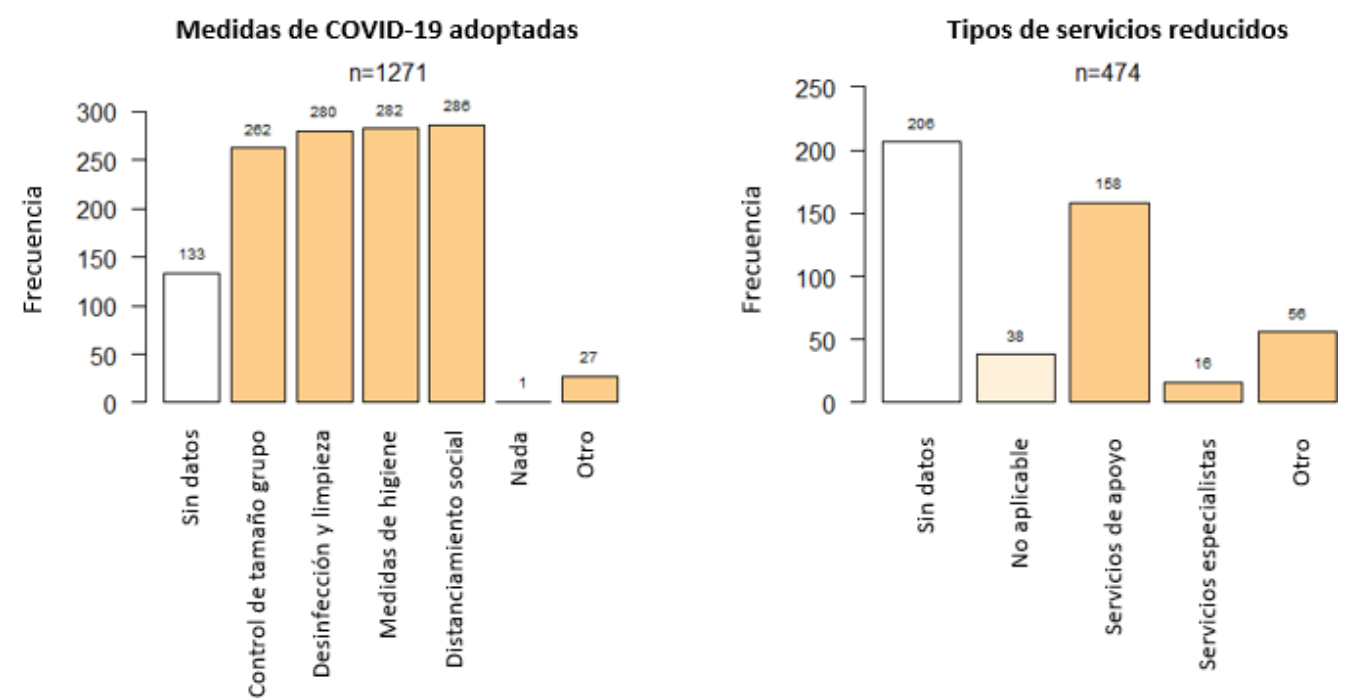

Figura 3. Medidas de COVID-19 adoptadas (a) y tipos de servicios reducidos (b) (preliminar). Aquí, $n$ indica el $n$ o de respuestas (se permitió a los encuestados seleccionar todas las que se aplicaban), no el no de encuestados.

El fuego puede propagarse a través del paisaje independientemente de las fronteras administrativas, y es común compartir recursos entre continentes, países, provincias/estados o municipios/condados. Debido al COVID-19, los encuestados indican una capacidad reducida para compartir recursos y servicios con otros que lo necesiten (Fig. 4a), y que hay un impacto sobre la oportunidad de recibir ayuda de otras regiones o países en caso de necesidad (Fig. 4b). Dado que las medidas de COVID-19 se centran en el distanciamiento social y en limitar el intercambio entre grupos y regiones, no es sorprendente que se reduzca el intercambio de recursos, como personal y aviación. No obstante, esto puede suponer un reto importante en caso de incendios forestales extremos o desafiantes.
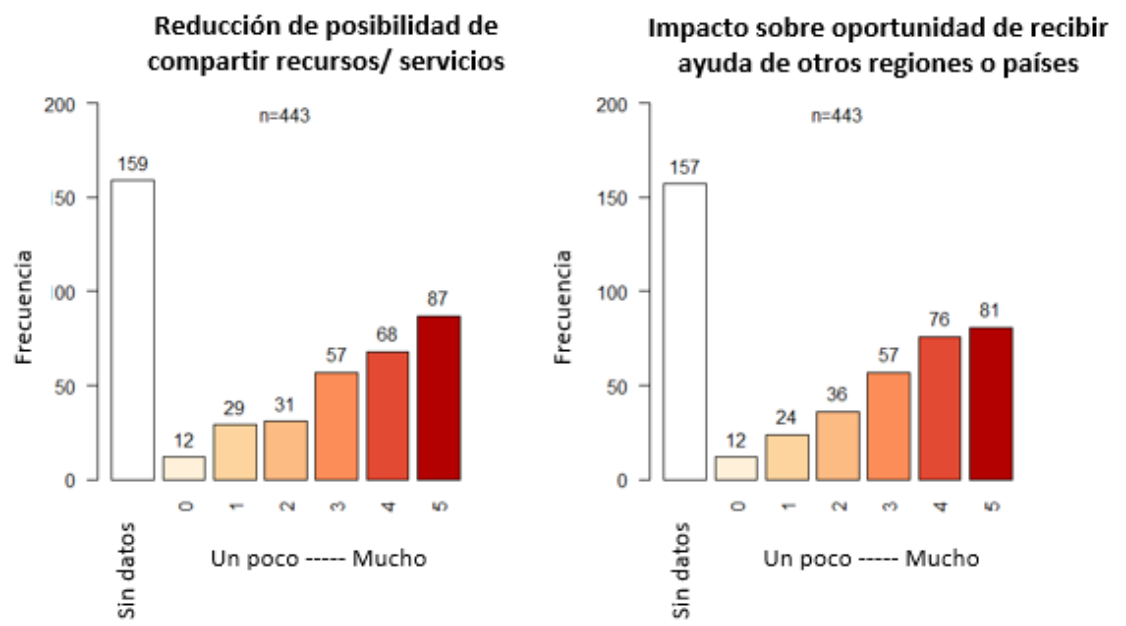

Figura 4. Efectos de COVID-19 en el intercambio (a) y la recepción (b) prevista de recursos en caso de necesidad (preliminar). Aquí, $n$ indica el $n$ o de encuestados. 
Para facilitar el intercambio y recepción de recursos durante COVID-19, se están elaborando listas de control sencillas, como la elaborada por el National Multi-Agency Coordinating Group (Fig. 5.)

\begin{tabular}{|c|c|c|c|}
\hline \multicolumn{4}{|c|}{ ORDERING UNIT -- Provide the following information in "Special Instructions" in resource order } \\
\hline & & Yes & No \\
\hline 1 & Confirm Best Management Practices are in place to mitigate COVID-19. & & \\
\hline 2 & $\begin{array}{l}\text { Description of any additional supply/equipment needs (self-sufficient, } \\
\text { food, water, extended camping equipment, etc.) }\end{array}$ & & \\
\hline 3 & $\begin{array}{l}\text { There is a medical plan in place with identified care facilities for COVID- } \\
19 \text { patients. }\end{array}$ & & \\
\hline 4 & $\begin{array}{l}\text { Describe the level of COVID-19 outbreak in the county where the fire is } \\
\text { located from the following website: https://coronavirus.jhu.edu/us-map }\end{array}$ & & \\
\hline \multicolumn{4}{|c|}{ SENDING UNIT - Is the following met? } \\
\hline & & Yes & No \\
\hline 1 & $\begin{array}{l}\text { All individuals filling the order have been screened using the MPHAT } \\
\text { Wildland Fire Screening Tool or their employing agency's equivalent. }\end{array}$ & & \\
\hline 2 & $\begin{array}{l}\text { The resource is equipped with PPE and supplies required to adhere to } \\
\text { COVID- } 19 \text { mitigation protocols during mobilization and for at least three } \\
\text { operational periods. }\end{array}$ & & \\
\hline 3 & $\begin{array}{l}\text { The resource is prepared to be self-sufficient regarding food and water } \\
\text { for at least the first three operational periods if driving. }\end{array}$ & & \\
\hline 4 & $\begin{array}{l}\text { The resource can meet any additional supply/equipment needs } \\
\text { identified in the Special Instructions section of the resource order. }\end{array}$ & & \\
\hline 5 & $\begin{array}{l}\text { There is an isolation/quarantine plan in place to use upon return to the } \\
\text { home unit that can be implemented if deemed necessary. }\end{array}$ & & \\
\hline
\end{tabular}

Figura 5. Lista de control interinstitucional para la movilización de recursos en el contexto COVID-19, elaborada por el National Multi-Agency Coordinating Group (NMAC, fuente).

Un resultado final que destacamos aquí en relación con la supresión de incendios es el impacto de COVID-19 en el número de personal por vehículo (Fig. 6a). Los datos muestran que, en un gran número de casos, este número se reduce como resultado de las medidas de COVID-19. Los encuestados destacan los problemas que esto provoca, no sólo porque puede faltar espacio para aumentar el número de vehículos en el escenario del incendio (Fig. 6b), sino también porque "es intercambiar un posible riesgo [COVID-19] por un riesgo conocido (conducir con fatiga)", ya que la conducción con fatiga "es una de las mayores causas de mortalidad en nuestro sector" (Fig. 6b).
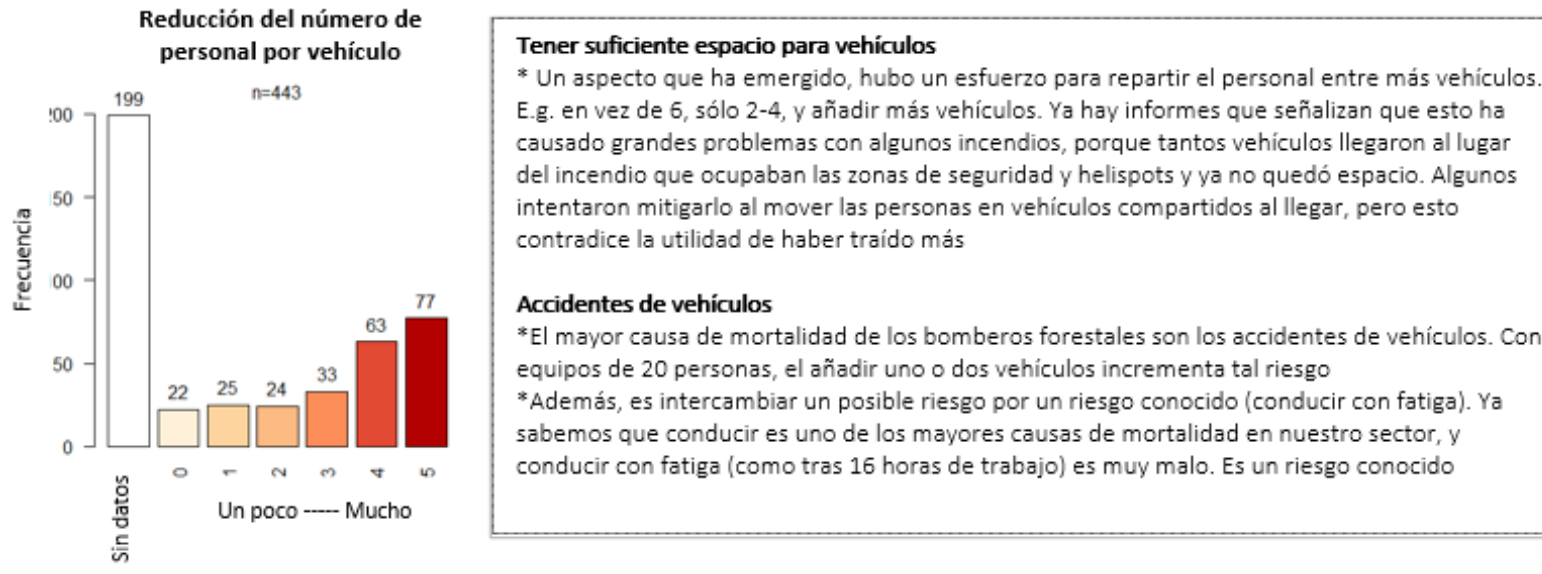

Figura 6. Efectos de COVID-19 en el (a) número de personal por vehículo (preliminar; $n$ es el no de encuestados), y (b) un ejemplo de comentario (traducido desde el inglés) en la encuesta sobre la reducción del número de personal por vehículo. 


\section{Capacitación y reducción de riesgos}

Aparte de los efectos de COVID-19 en la gestión general y la supresión de incendios, como se ha señalado arriba, los encuestados indican efectos considerables en la formación y capacitación; la participación comunitaria previa a la temporada; la gestión del combustible; y otras actividades de reducción de riesgos (Fig. 7). De las preguntas abiertas queda claro que esos efectos se deben a la cancelación o reducción de esas actividades. Se estima que la reducción de estas actividades impactará no sólo en el riesgo de incendios para las comunidades, sino también en el riesgo para quienes trabajan en la gestión de incendios. Esto además señaliza hacia el posible impacto a largo plazo que tiene COVID-19 sobre la gestión de incendios.
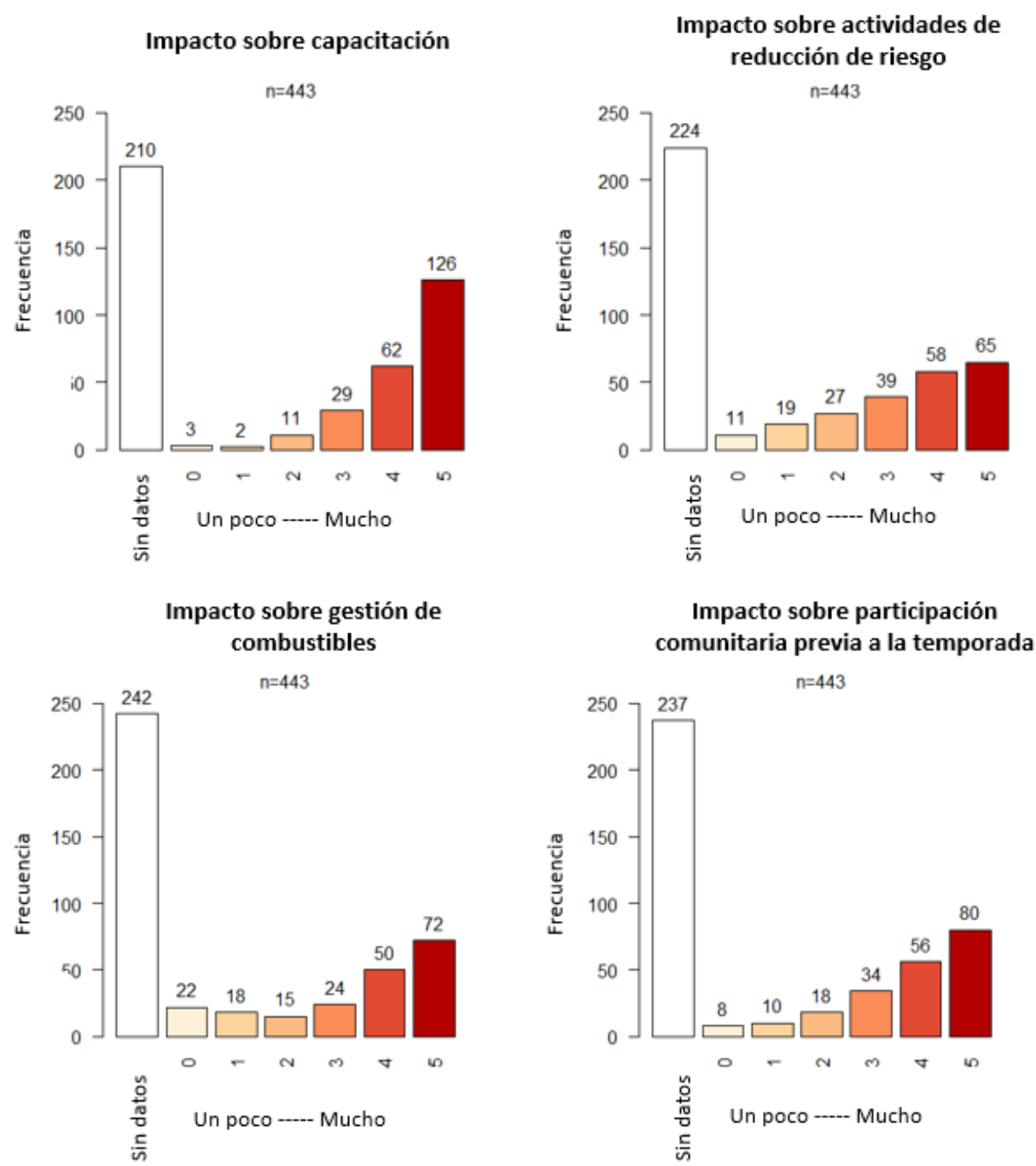

Figura 7. Efectos de COVID-19 en la capacitación y en la reducción de riesgos (preliminar). N es el no de encuestados. 


\section{Necesidad de pruebas rápidas de detección}

Una gran preocupación ¿Es posible contagiarse del 2019-nCoV a través de una persona que no presenta síntomas? actual en la comunidad de bomberos es la falta de pruebas de COVID-19 para los bomberos forestales.

Aún no está claro hasta qué punto esto es un problema a nivel mundial, pero en el

Conocer el periodo en que los pacientes infectados pueden propagar el virus a otras personas es fundamental para las medidas destinadas a controlar el brote. Se necesita información médica detallada de las personas infectadas para determinar el periodo de infecciosidad del 2019-nCoV. Según los últimos informes, es posible que las personas infectadas por el 2019-nCoV puedan contagiar la infección antes de mostrar síntomas apreciables. Con todo, según los datos actualmente disponibles, las personas que presentan síntomas son las que están ocasionando la mayor parte de la propagación del virus.

Figura 8. Información del OMS sobre propagación del COVID-19 (fuente) caso de los EE.UU. no se realizan pruebas de COVID-19 a menos que alguien muestra síntomas de COVID-19. Esto es a pesar de que se sabe que personas sin síntomas pueden propagar el virus (Fig. 8). En los EE.UU. hay grandes campamentos de bomberos en los que se concentran grandes grupos de bomberos, por el cual el riesgo es muy alto de que el virus se propague sin saberlo. Sin embargo, no se disponen de pruebas periódicas y no hay suficiente equipo de protección personal, como se resaltó en un llamamiento a la acción a los senadores a la Casa Blanca el 18 de mayo de 2020 (enlace). Los encuestados muestran preocupación por la falta de pruebas, como se ilustra en la Fig. 9. Para mantener la seguridad de las personas y asegurar la continuación de la gestión de los incendios forestales, es esencial realizar frecuentemente pruebas rápidas de detección de COVID-19.

* [...] Los campamentos de incidentes siempre han sido lugares terribles para mantener condiciones de higiene aceptables. 90\% de las personas que conozco, incluido mí mismo, se enferman en estas ocasiones. ¿Y ahora qué? ¿Cuarentena? ¿No puedes hacerte una prueba, así que vuélvete a casa y expón a tu familia?

* [...] El PERSONAL DEBE SER TESTADO ANTES DE CADA MOVILIZACIÓN! SINO NO HAY NINGUNA GARANTÍA QUE CASOS ASINTOMÁTICOS O PRE-SINTOMÁTICOS DE COVID-19 NO ESTEN DENTRO DE LOS GRUPOS DE PERSONAL. Estaría genial para tener más ciencia y más pruebas de inmunidad, porque si bomberos recuperados del COVID-19 pueden participar en incendios, puede que no habría la necesidad de adherirse tan estrictamente a todas las medidas de COVID-19

Figura 9. Ejemplo de un comentario (traducido desde el inglés) en la encuesta sobre las pruebas de COVID-19

\section{Perspectivas para el Informe 2}

Esperamos publicar el análisis completo de las respuestas a la encuesta en el Informe 2 a mediados de junio, que estará disponible en la página web de la biblioteca de la Universidad de Wageningen aquí (este enlace estará inactivo hasta que el informe esté disponible). Este análisis abordará las cuatro secciones del estudio: 1) caracterización de la organización del encuestado; 2) gestión general de los incendios; 3 ) extinción de incendios (a nivel operacional, mando de incidentes y personal de apoyo especializado, a nivel de tripulación, medios aéreos, estrategias y tácticas); y 4) capacitación en materia de incendios, reducción de riesgos, preparación y recuperación.

\section{Recursos adicionales}

A continuación incluimos dos oportunidades para obtener más información, presentadas en webinars. No obstante, esta no es una lista completa. Si desea que su actividad o material informativo sea compartido en nuestros informes, por favor contáctenos a través de la información de contacto indicada en la primera página. 
- "COVID-19 e incendios forestales: una serie de webinars", organizado por Intterra y la Western Fire Chiefs Association (WFCA) en los EE.UU., centrándose en las cuestiones y las orientaciones que se difunden en el servicio de bomberos. Comienza el miércoles 27 de mayo y la participación es gratuita pero es necesario registrarse. Se puede encontrar más información aquí. Se espera que el idioma sea el inglés.

- 'O reflexo do COVID-19 no sistema de defesa da floresta contra incêndios em 2020', webinar de 2 horas organizado por el Centro de Estudos sobre Incêndios Florestais da ADAI (Universidad de Coimbra, Portugal). El webinar se celebró el 12 de mayo de 2020, y en ello participaron una amplia gama multidisciplinaria de personas de los sectores médicos y de emergencia, y puede verse aquí. El idioma es el portugués.

\section{Referencias}

Moore, P., Hannah, B., de Vries, J., Poortvliet, M., Steffens, R., Stoof, C.R. (2020). Wildland Fire Management under COVID-19. Brief 1, Review of Materials. Wageningen University, The Netherlands. https://doi.org/10.18174/521344

\section{Agradecimientos}

Agradecemos a todos los encuestados por tomar el tiempo de completar la encuesta, que con ello han contribuido a que otros puedan aprender de la experiencia adquirida alrededor todo el mundo. Somos conscientes de que la preparación de la gestión de incendios en el marco de COVID-19 requiere mucho tiempo y apreciamos mucho su ayuda. También agradecemos a Steve Miller por compartir la lista de verificación de movilización interinstitucional (Fig. 5).

\section{Nota de la traductora}

Bajo la actual emergencia del COVID19, se ha considerado pertinente realizar una traducción inmediata del informe original, en inglés, al español, para garantizar que llegue a la mayor cantidad de personas y organismos posibles. No obstante, la traducción puede albergar pequeños errores por la rapidez de su elaboración, por lo cual recomendamos que, en caso de duda, se consulte el original en inglés aquí. 